Article

\title{
A Co(II)-Hydrazone Schiff Base Single Ion Magnet Exhibiting Field Induced Slow Relaxation Dynamics ${ }^{\dagger}$
}

\author{
Dipali Sadhukhan ${ }^{1, *}$, Prithwi Ghosh ${ }^{2}$, Carlos J. Gómez-García ${ }^{3}$ (ID and Mathieu Rouzieres ${ }^{1}$ \\ 1 Centre de Recherche Paul Pascal, Université de Bordeaux, UMR 5031, 115 Avenue du Dr. A. Schweitzer, \\ 33600 Pessac, France; rouzieres@crpp-bordeaux.cnrs.fr \\ 2 Institute of Biological Chemistry, Washington State University, Pullman, WA 99164, USA; \\ prithwi11@gmail.com \\ 3 Instituto de Ciencia Molecular (ICMol), Dpto. Química Inorgánica, Universidad de Valencia, 46980 Paterna, \\ Spain; carlos.gomez@uv.es \\ * Correspondence: dipali@crpp-bordeaux.cnrs.fr; Tel.: +33-758715798 \\ + Dedicated to the memory of Professor Samiran Mitra: an inspiring mentor and researcher.
}

Received: 30 October 2018; Accepted: 1 December 2018; Published: 7 December 2018

check for updates

\begin{abstract}
An octahedral Co(II) complex with $N^{\prime}$-(2-hydroxybenzylidene)acetohydrazide Schiff base ligand [HL] forms a 3D supramolecular assembly supported by non-coordinating $\mathrm{ClO}_{4}{ }^{-}$ions and $\mathrm{H}_{2} \mathrm{O}$ molecules. Individual spin centres are non-interacting and give rise to significant spin-orbit coupling, resulting in field induced slow magnetisation relaxation; which is characteristic of Single Ion Magnet (SIM) behaviour.
\end{abstract}

Keywords: $\mathrm{Co}(\mathrm{II})-\mathrm{Hydrazone}$ complex; Single ion magnet; slow magnetic relaxation; magnetic anisotropy; Supramolecular interaction

\section{Introduction}

In the last two decades Single Molecule Magnets (SMM) have received considerable research interest for their potential applications in high density information storage, quantum computing and spintronics [1-4]. The characteristic slow magnetic relaxation at low temperature is associated with a large energy barrier originating from the effect of molecular anisotropy $(D)$ on a high spin ground state (S) and is expressed by $U=S^{2}|D|$ for integer and $U=\left(S^{2}-\frac{1}{4}\right)|D|$ for half integer spins. Although most SMM are polynuclear metal complexes, they can also contain a single anisotropic paramagnetic centre. These compounds are known as Single Ion Magnets (SIMs) or mononuclear SMMs. Since the discovery by Ishikawa et al. in 2003 [4] many of these SIMs have been prepared and studied in the past decade. Most of them are based on lanthanide [5-8] and actinide [9-12] paramagnetic centres and some of the recent developments on Dy SIMs have led to very high blocking temperatures of ca. 60-80 K [13-15]. The SIM behaviour has also been observed in 3d transition metal complexes which mainly include three to five coordinate species: trigonal planar and trigonal pyramidal $\mathrm{Fe}(\mathrm{II})$ [16-18] and tetrahedral and square pyramidal Co(II) $[19,20]$ complexes. A rarer example is a two coordinated linear $\mathrm{Ni}^{\mathrm{I}}$ complex [21]. The low coordination number is necessary to minimize the effect of ligand field thus reducing the $3 \mathrm{~d}$ orbital splitting energy, thereby enhancing the magnetic anisotropy. Mononuclear Co(II) complexes remain as interesting candidates for SIM, thanks to the first order spin-orbit coupling in the ground state of Co(II) coupled with ligand field effects leading to high magnetic anisotropy. The first reported Co(II) SIM was a distorted square pyramidal complex [22] where the anisotropy is related to the significant distortion of the Co(II) ion from the basal plane. Afterwards a number of tetrahedral Co(II) SIMs have been explored with varying relaxation barriers $\left(14-230 \mathrm{~cm}^{-1}\right)$ and axial ZFS parameter $D\left(-5\right.$ to $\left.-160 \mathrm{~cm}^{-1}\right)$ [23-28] where heavier donor atoms such as S, Se, P or I and 
the tight bite angles of the ligands enhance the magnetic anisotropy. In contrast to tetrahedral Co(II) SIMs, octahedral systems are rarely reported [29-36]. For distorted octahedral Co(II) ions the axial ZFS parameter $D$ is expected to be positive owing to the easy plane $(x y)$ of anisotropy [37] but in few cases it has been found to be negative [38], especially in mer-directing ligands where the octahedral geometry is distorted towards trigonal prismatic geometry [39].

Herein we report the synthesis, crystal structure and the static and dynamic magnetic behaviour of a new SIM based on octahedral Co(II) ion coordinated by a mer-directing ONO donor hydrazone Schiff base ligand and having a negative easy axis of anisotropy. Moreover, this is the first example of a ligand, solvent and anion assisted 3D supramolecular assembly where the magnetic coupling between two spin centres is negligibly small due to large Co $\cdots$ Co separation $(\sim 6.28 \AA)$ and absence of $\pi \cdots \pi$ stacking interaction between the ligand aromatic rings. Hence the intrinsic SIM behaviour is preserved.

\section{Results and Discussion}

\subsection{X-ray Crystal Structure of $\left[\mathrm{Co}(\mathrm{HL})_{2}\right]\left(\mathrm{ClO}_{4}\right)_{2} \cdot 2 \mathrm{H}_{2} \mathrm{O}(\mathbf{1})$}

A perspective view of $\mathbf{1}$ is shown in Figure 1 and the bonding parameters are listed in Table 1. In 1 the CoII ion forms a bis-chelate complex with two tridentate ONO donor hydrazone ligands oriented in a mer-configuration around the metal centre. The ligands coordinate to the Co(II) ion via the ketonic oxygens (O1, O2), the azomethine nitrogens (N3, N4) and the phenolic oxygens $(\mathrm{O} 3, \mathrm{O} 4)$. The two disordered perchlorates centred on $\mathrm{Cl} 2$ and $\mathrm{Cl} 3$ appear with an occupancy factor of $\frac{1}{2}$ whereas the perchlorate anion centred on $\mathrm{Cl1}$ appears with an occupancy factor of one, giving a total of two perchlorate anions to balance the Co(II) charge. This stoichiometry indicates that the ligand is coordinated to the metal centre in its neutral form (as HL). The Co(II) ion adopts a distorted octahedral coordination geometry. The twelve cis angles subtended at the metal centre by adjacent donor atoms range from $77.90(7)$ to $107.42(7)^{\circ}$ and the three trans angles are O4-Co1-O2 $=158.26(7)^{\circ}$, N4-Co1-N3 $=173.64(7)^{\circ}$ and O1-Co1-O3 $=161.26(7)^{\circ}$ confirm the distortion from the ideal octahedral geometry. The distortion from the idealized geometry may be attributed to the restricted bite angles imposed by the planar tridentate Schiff bases. The mean equatorial plane is formed by the phenolic oxygens (O3 and $\mathrm{O} 4)$ and the ketonic oxygens (O1 and $\mathrm{O} 2)$ while two axial sites are occupied by the two azomethine nitrogen atoms (N3 and N4). The mean planes defined by the donor atoms of the two ligands are almost orthogonal to each-other with a dihedral angle of $89.49^{\circ}$ as expected for a mer-geometry.

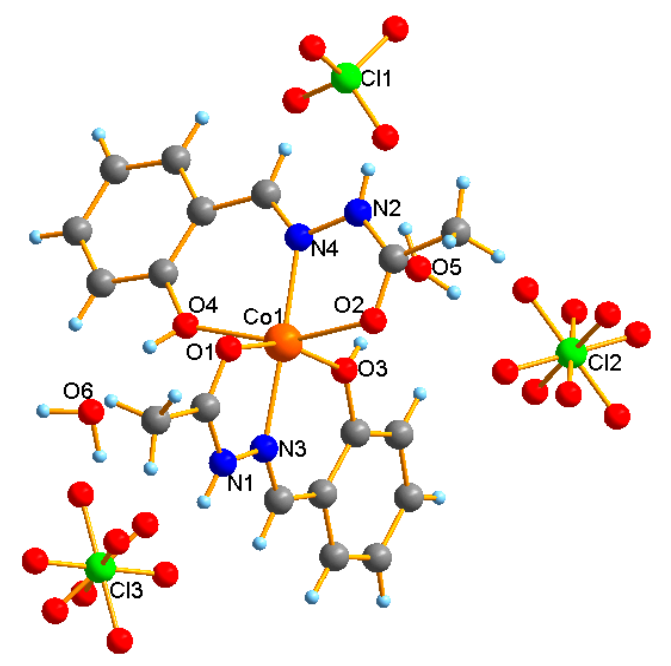

Figure 1. The asymmetric unit of complex 1. 
Table 1. Selected bond distances $(\AA)$ and angles $\left(^{\circ}\right)$ of $\mathbf{1}$.

\begin{tabular}{cccccc}
\hline Atoms & Distance $(\AA)$ & Atoms & Angle $\left(^{\circ}\right)$ & Atoms & Angle $\left(^{\circ}\right)$ \\
\hline Co1-O1 & $2.0804(2)$ & O4-Co1-O2 & $158.26(7)$ & O1-Co1-N4 & $106.53(7)$ \\
Co1-O2 & $2.0911(2)$ & O4-Co1-O1 & $87.18(7)$ & O3-Co1-N4 & $91.30(7)$ \\
Co1-O3 & $2.0803(2)$ & O2-Co1-O1 & $87.33(7)$ & O4-Co1-N3 & $91.94(7)$ \\
Co1-O4 & $2.0929(2)$ & O4-Co1-O3 & $100.71(7)$ & O2-Co1-N3 & $107.42(7)$ \\
Co1-N3 & $2.0713(2)$ & O2-Co1-O3 & $91.03(7)$ & O1-Co1-N3 & $77.90(7)$ \\
Co1-O22 & $2.0750(2)$ & O1-Co1-O3 & $161.26(7)$ & O3-Co1-N3 & $84.82(7)$ \\
& & O4-Co1-N4 & $83.82(7)$ & N4-Co1-N3 & $173.64(7)$ \\
& & O2-Co1-N4 & $77.63(7)$ & & \\
\hline
\end{tabular}

There are several intermolecular hydrogen bonds as can be seen in Figure 2 and Table 2 . A three-dimensional supramolecular network is formed by centrosymmetric intermolecular hydrogen bonding mediated by the water molecules and the perchlorate anions as can be viewed along different planes. The perchlorate centred at $\mathrm{Cl} 1$ is connected to the imine nitrogen (N2) of a complex unit through a N2-H21 $\cdots \mathrm{O} 7 \mathrm{H}$-bond. The perchlorates centred at $\mathrm{Cl} 2$ and $\mathrm{Cl} 3$ are situated on an inversion centre and are symmetrically connected to the imine nitrogen (N1) of two complex units via. N1-H11 ‥O11 and $\mathrm{N} 1-\mathrm{H} 11 \cdots \mathrm{O} 14$ interactions. The $\mathrm{O}-\mathrm{H}$ groups from a complex unit are linked to the solvent $\mathrm{H}_{2} \mathrm{O}$ molecules via $\mathrm{O} 3-\mathrm{H} 31 \cdots \mathrm{O} 5$ and $\mathrm{O} 4-\mathrm{H} 41 \cdots \mathrm{O} 6 \mathrm{H}$-bonds. The $\mathrm{H}_{2} \mathrm{O}$ molecules are further linked to the $\mathrm{ClO}_{4}$ molecules to extend the supramolecular network in different directions. The shortest distance between the adjacent Co1 centres is $6.28 \AA$.
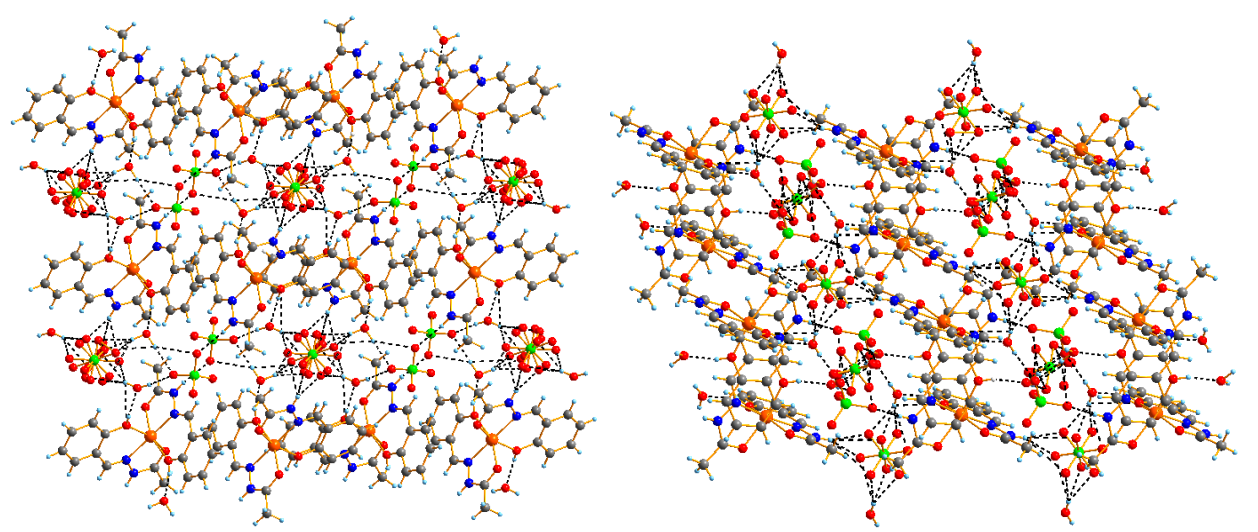

Figure 2. The $3 \mathrm{D}$ hydrogen bonded network in 1 mediated by $\mathrm{H}_{2} \mathrm{O}$ and $\mathrm{ClO}_{4}{ }^{-}$viewed along the $b c$ (left) and $a b$ (right) planes.

Table 2. Hydrogen-bond parameters of $\mathbf{1}$.

\begin{tabular}{|c|c|c|c|c|}
\hline $\mathrm{D}-\mathrm{H} \cdots \mathrm{A}$ & $\mathrm{d}(\mathrm{D}-\mathrm{H}) \AA$ & $\mathrm{d}(\mathrm{H} \cdots \mathrm{A}) \AA$ & $\mathrm{d}(\mathrm{D} \cdots \mathrm{A}) \AA$ & 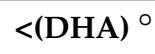 \\
\hline 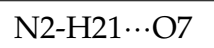 & 0.85 & 2.05 & $2.891(4)$ & 173 \\
\hline N1-H11O11 & 0.84 & 2.12 & $2.929(4)$ & 161 \\
\hline N1-H11 ‥O14 & 0.84 & 2.09 & $2.894(4)$ & 159 \\
\hline 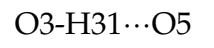 & 0.82 & 1.84 & $2.564(4)$ & 146 \\
\hline 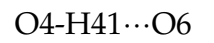 & 0.82 & 1.75 & $2.541(4)$ & 163 \\
\hline 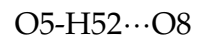 & 0.83 & 2.07 & $2.872(4)$ & 165 \\
\hline O5-H51O11 & 0.82 & 2.33 & $3.093(4)$ & 155 \\
\hline 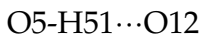 & 0.82 & 1.98 & $2.588(4)$ & 130 \\
\hline O5-H51‥O13 & 0.82 & 2.45 & $3.245(4)$ & 163 \\
\hline O5-H51‥O14 & 0.82 & 2.56 & $3.224(4)$ & 138 \\
\hline O6-H1 $\cdots \mathrm{O} 8$ & 0.90 & 1.98 & $2.886(4)$ & 180 \\
\hline $\mathrm{O} 6-\mathrm{H} 2 \cdots \mathrm{O} 15$ & 0.90 & 2.56 & $3.138(4)$ & 122 \\
\hline $\mathrm{O} 6-\mathrm{H} 2 \cdots \mathrm{O} 16$ & 0.90 & 1.76 & $2.660(4)$ & 180 \\
\hline $\mathrm{O} 6-\mathrm{H} 2 \cdots \mathrm{O} 17$ & 0.90 & 2.48 & $3.248(4)$ & 143 \\
\hline
\end{tabular}




\subsection{Magnetic Studies}

The thermal variation of the molar magnetic susceptibility per $\mathrm{Co}(\mathrm{II})$ ion times the temperature $\left(\chi_{m} T\right.$ vs. $T$ ) for complex 1 (Figure 3) shows a $\chi_{m} T$ value of $2.30 \mathrm{~cm}^{3} \mathrm{~K} \mathrm{~mol}^{-1}$ at $300 \mathrm{~K}$, which is significantly higher than the expected value for one isolated $\mathrm{Co}(\mathrm{II})$ ion $(S=3 / 2)$ with $g=2$ $\left(1.875 \mathrm{~cm}^{3} \mathrm{~K} \mathrm{~mol}^{-1}\right)$ but within the range $2.1-3.4 \mathrm{~cm}^{3} \mathrm{~K} \mathrm{~mol}^{-1}$ observed for Co(II) ions with a considerable orbital contribution $[22,39,40]$. On decreasing the temperature, $\chi_{m} T$ remains almost constant down to $60 \mathrm{~K}$, corresponding to the Curie-type behaviour of a non-interacting Co(II) centre. The decrease observed below $60 \mathrm{~K}$ to reach a value of $1.6 \mathrm{~cm}^{3} \mathrm{~K} \mathrm{~mol}^{-1}$ at $1.8 \mathrm{~K}$ (with $0.1 \mathrm{~T}$ field) is very similar to the one observed in other mononuclear $\mathrm{Co}(\mathrm{II})$ complexes with similar tridentate meridional ligands [37]. Accordingly, we have simultaneously fit the thermal variation of $\chi_{m} T$ and the isothermal magnetizations at 1.9, 3, 5 and $8 \mathrm{~K}$ (Figures 3 and 4) using the following Hamiltonian with $\mathrm{S}=3 / 2$ with the program PHI [41]:

$$
H=D\left\{S_{z}^{2}-\left[\frac{S(S+1)}{3}\right]\right\}+E\left(S_{x}^{2}-S_{y}^{2}\right)+\mu_{B} g H
$$

where $D$ and $E$ are, respectively, the axial and rhombic zero field splitting parameters, $\mu_{B}$ is the Bohr magneton and $H$ is the applied dc field. To avoid over-parametrization, we have fixed $g_{x}=g_{y} \neq g_{z}$ and we have varied $g_{x}, g_{y}$ and $g_{z}$ from 1.8 to 3.2 and the diagonal components of $D$ from 100 to $-100 \mathrm{~cm}^{-1}$. A very good fit for $\chi_{m} T$ vs. $T$ and $M$ vs. $H$, simultaneously, in the whole temperature range was obtained for $D=-23.8 \mathrm{~cm}^{-1}, E=7.0 \mathrm{~cm}^{-1}, g_{z}=2.48$ and $g_{x}=g_{y}=2.16$ (Figures 3 and 4). The Co(II) ion has an easy axis anisotropy with a relevant rhombic distortion given by $|E / D|=0.294$ in good agreement with previous reports [37].

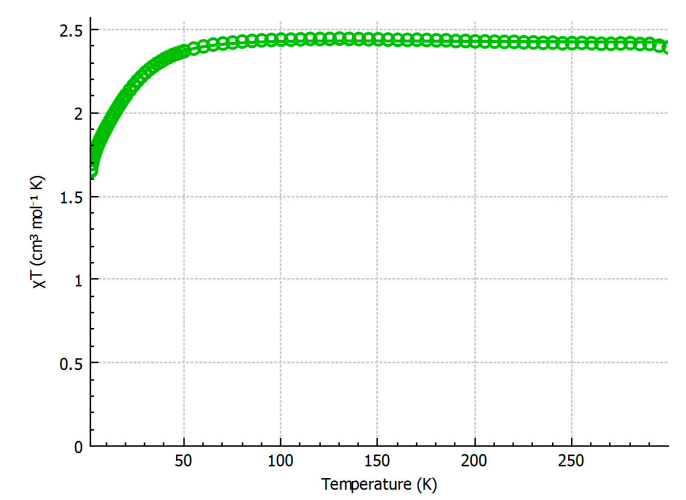

Figure 3. Thermal variation of $\chi_{m} T$ for 1 between 300 and $2 \mathrm{~K}$ with $1000 \mathrm{Oe}(0.1 \mathrm{~T})$. Solid line shows the best fit to the model (see text).

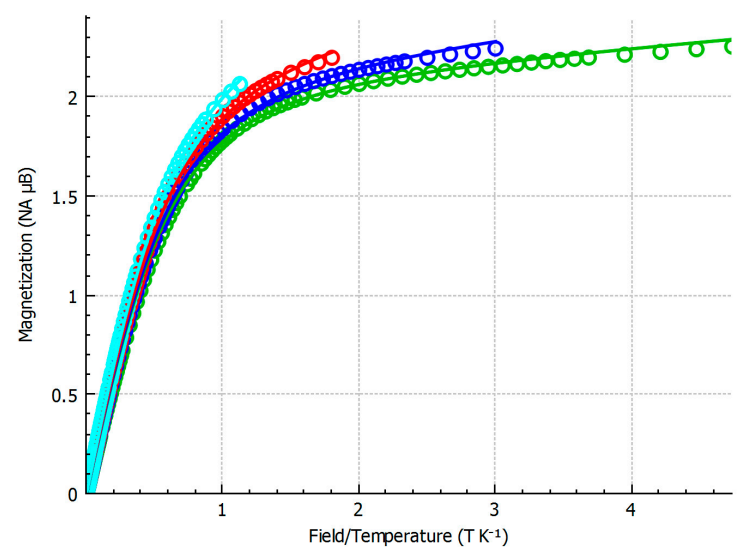

Figure 4. Isothermal reduced magnetization of compound 1 at $1.9 \mathrm{~K}$ (green), $3.0 \mathrm{~K}$ (dark blue), $5.0 \mathrm{~K}$ (red), and $8.0 \mathrm{~K}$ (cyan). Solid lines are the best-fit parameters to the model (see text). 
The isothermal magnetization measurements up to $9 \mathrm{~T}$ performed in the temperature range 1.9-8 K (Figure 4) show that even with applied fields of $9 \mathrm{~T}$ at $1.9 \mathrm{~K}$, the magnetization does not reach saturation and the reduced magnetization at different temperatures are not superimposable, confirming the intrinsic anisotropy of the $\mathrm{Co}(\mathrm{II})$ ion in compound $\mathbf{1}$.

AC susceptibility measurements have been performed in order to check the possible presence of a SMM behaviour. No AC signal was observed with a zero applied DC field, but a frequency dependent signal is observed when a DC field is applied at $2 \mathrm{~K}$ (Figure 5), suggesting the presence of quantum tunnelling magnetization (QTM) mechanism operating at low temperatures to account for the fast relaxation of the magnetization at zero applied field. Application of a DC magnetic field splits the energy of the $\pm \mathrm{M}_{S}$ Kramers doublets, reducing or cancelling the quantum tunnelling mechanism of the relaxation. Accordingly, the relaxation process becomes slower, resulting in the appearance of a frequency dependent AC signal (Figures 6 and 7).

The intensity of the AC signal increases and shows a maximum that shifts to lower frequencies as the field increases to reach a minimum frequency for DC applied fields of ca. 800 G (Figure 5). Accordingly, we have performed a detailed study of the temperature and frequency dependence of the AC signal for 1 with an applied DC field of 800 G (Figures 6 and 7).

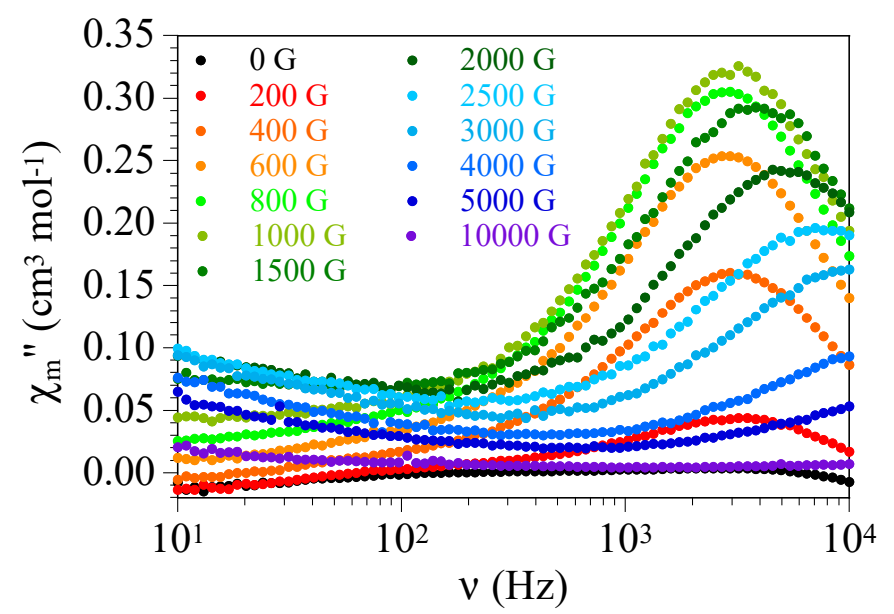

Figure 5. Frequency dependence of the $\chi_{m}{ }^{\prime \prime}$ signal for compound $\mathbf{1}$ at $2 \mathrm{~K}$ with different applied DC fields.

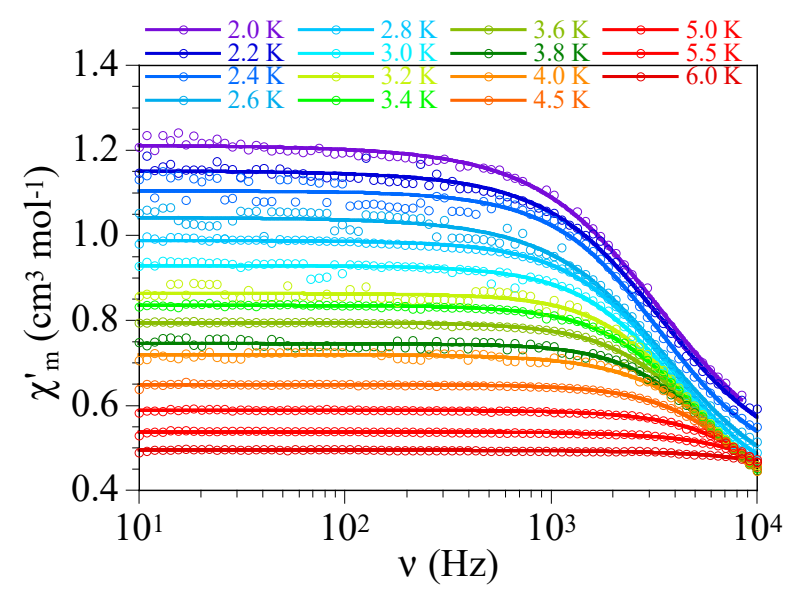

Figure 6. Frequency dependence of the in-phase AC susceptibility for $\mathbf{1}$ with an applied DC field of 800 Oe at different temperatures. Solid line is the best fit to the Debye model (Equation (2)). 


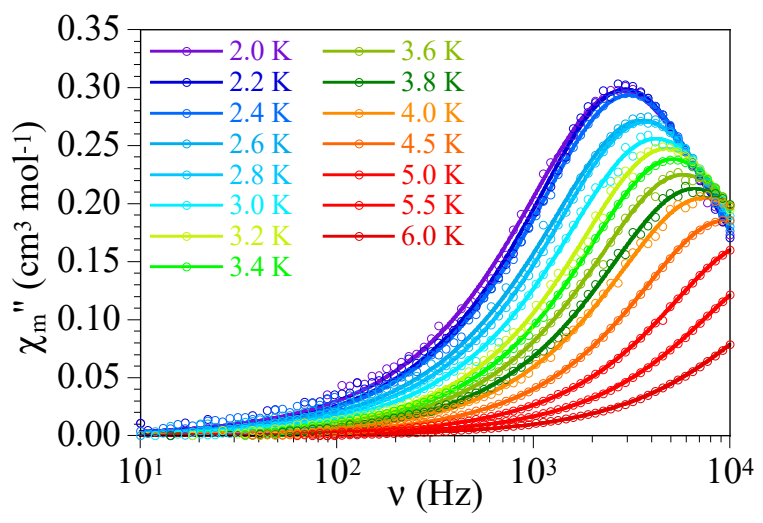

Figure 7. Frequency dependence of the out-of-phase AC susceptibility for $\mathbf{1}$ with an applied DC field of 800 Oe at different temperatures. Solid line is the best fit to the Debye model (Equation (3)).

The frequency-dependence of the in-phase $\left(\chi_{m}{ }^{\prime}\right)$ and out of phase $\left(\chi_{m}{ }^{\prime \prime}\right)$ signals for a DC field of $800 \mathrm{G}$ has been fit with the Debye model using the following equations [42]:

$$
\begin{aligned}
& \chi^{\prime}(\omega)=\chi_{S}+\frac{\left(\chi_{T}-\chi_{S}\right)\left[1+(\omega \tau)^{1-\alpha} \operatorname{sen} \frac{1}{2} \alpha \pi\right]}{1+2(\omega \tau)^{1-\alpha} \operatorname{sen} \frac{1}{2} \alpha \pi+(\omega \tau)^{2(1-\alpha)}} \\
& \chi^{\prime \prime}(\omega)=\chi_{S}+\frac{\left(\chi_{T}-\chi_{S}\right)(\omega \tau)^{1-\alpha} \cos \frac{1}{2} \alpha \pi}{1+2(\omega \tau)^{1-\alpha} \operatorname{sen} \frac{1}{2} \alpha \pi+(\omega \tau)^{2(1-\alpha)}}
\end{aligned}
$$

where $\alpha$ corresponds to the distribution of relaxation times, $\chi_{S}$ and $\chi_{T}$ are the adiabatic and isothermal susceptibilities, respectively, $\omega=2 \pi \gamma$, corresponds to the angular frequency and $\tau$ is the relaxation time. These equations give very good fits in the temperature range 2-6 K (solid lines in Figures 6 and 7) with the parameters shown in Table 3.

Table 3. Parameters obtained from the fit of the out-of-phase AC signal ( $\left.\chi_{m}{ }^{\prime \prime}\right)$ of compound 1 to the

\begin{tabular}{|c|c|c|c|c|}
\hline $\mathrm{T}(\mathrm{K})$ & $\alpha$ & $\chi_{s}\left(\mathrm{~cm}^{3} \mathrm{~mol}^{-1}\right)$ & $\chi_{T}\left(\mathrm{~cm}^{3} \mathrm{~mol}^{-1}\right)$ & $\tau_{0}(s)$ \\
\hline 2.0 & 0.0999 & 0.658 & 1.344 & $9.63 \times 10^{-7}$ \\
\hline 2.1 & 0.0881 & 0.663 & 1.337 & $9.40 \times 10^{-7}$ \\
\hline 2.2 & 0.0532 & 0.676 & 1.324 & $9.42 \times 10^{-7}$ \\
\hline 2.3 & 0.0458 & 0.683 & 1.317 & $9.04 \times 10^{-7}$ \\
\hline 2.4 & 0.0542 & 0.680 & 1.320 & $9.06 \times 10^{-7}$ \\
\hline 2.5 & 0.0590 & 0.685 & 1.315 & $8.64 \times 10^{-7}$ \\
\hline 2.6 & 0.0594 & 0.701 & 1.299 & $7.71 \times 10^{-7}$ \\
\hline 2.7 & 0.0612 & 0.708 & 1.292 & $7.26 \times 10^{-7}$ \\
\hline 2.8 & 0.0434 & 0.710 & 1.290 & $7.47 \times 10^{-7}$ \\
\hline 2.9 & 0.0370 & 0.718 & 1.282 & $7.09 \times 10^{-7}$ \\
\hline 3.0 & 0.0502 & 0.723 & 1.277 & $6.60 \times 10^{-7}$ \\
\hline 3.2 & 0.0280 & 0.742 & 1.258 & $5.87 \times 10^{-7}$ \\
\hline 3.4 & 0.0214 & 0.754 & 1.247 & $5.42 \times 10^{-7}$ \\
\hline 3.6 & 0.0213 & 0.766 & 1.234 & $4.86 \times 10^{-7}$ \\
\hline 3.8 & 0.0377 & 0.774 & 1.226 & $4.20 \times 10^{-7}$ \\
\hline 4.0 & 0.0326 & 0.784 & 1.216 & $3.76 \times 10^{-7}$ \\
\hline 4.5 & 0.0121 & 0.811 & 1.189 & $2.91 \times 10^{-7}$ \\
\hline 5.0 & 0.0158 & 0.830 & 1.170 & $2.09 \times 10^{-7}$ \\
\hline 5.5 & 0.0209 & 0.850 & 1.150 & $1.46 \times 10^{-7}$ \\
\hline 6.0 & 0.0361 & 0.872 & 1.129 & $9.57 \times 10^{-8}$ \\
\hline
\end{tabular}
Debye model (Equations (2) and (3)). 
As can be seen, the $\alpha$ parameter is close to zero $(\alpha<0.1$, Table 3$)$ in the studied temperature range, indicating a narrow distribution of the relaxation times. This result is further confirmed with the fit of the Cole-Cole or Argand plot ( $\chi_{m}{ }^{\prime \prime}$ vs. $\chi_{m}{ }^{\prime}$, Figure 8$)$ that shows symmetrical semi-circular plots (indicative of a single relaxation process) that can be fit with very low $\alpha$ values in all cases $(\alpha<0.1)$ using the generalized Debye model [43]:

$$
\chi_{m}^{\prime \prime}=-\frac{\chi_{T}-\chi_{s}}{2 \tan [(1-\alpha) \pi / 2]}+\sqrt{\left(\chi^{\prime}-\chi_{s}\right)\left(\chi_{T}-\chi^{\prime}\right)+\frac{\left(\chi_{T}-\chi_{s}\right)^{2}}{4 \tan ^{2}[(1-\alpha) \pi / 2]}}
$$

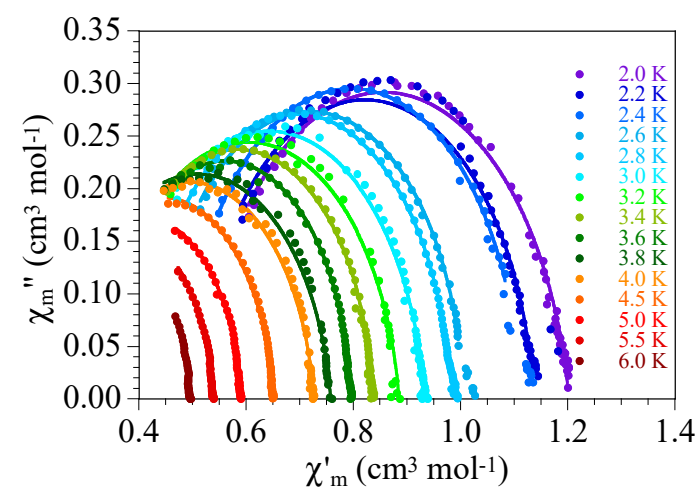

Figure 8. $\chi_{m}{ }^{\prime}$ vs. $\chi_{m}{ }^{\prime \prime}$ plot for compound 1 at different temperatures. Solid lines are the fit to the generalized Debye model (Equation (4)).

The plot of $1 / \tau$ as a function of the temperature (Figure 9) shows a linear regime at low temperatures $(T \leq 3 \mathrm{~K})$ with a curvature at higher temperatures, indicative of the coexistence of Orbach, Raman and direct relaxation processes. Accordingly, we have fit the spin relaxation time with the following equation [44]:

$$
\tau^{-1}=\tau_{0}^{-1} \exp \left(\frac{-U_{e f f}}{k T}\right)+C T^{n}+A T
$$

where the first term corresponds to the Orbach process, the second term is the Raman process (with $n=9$ for Kramer ions) and the third term is the single phonon direct process. In order to reduce the number of adjustable parameters, we have fixed $n=9$ (the value obtained when it is allowed to vary freely was 9.18). Equation (5) reproduces very well the thermal dependence of the relaxation time of compound 1 with $\tau_{0}^{-1}=7.4 \times 10^{7} \mathrm{~s}^{-1}, U_{e f f}=19.7 \mathrm{~K}=13.7 \mathrm{~cm}^{-1}, C=0.48 \mathrm{~s}^{-1} \mathrm{~K}^{-9}$ and $A=4.8 \times 10^{5} \mathrm{~s}^{-1} \mathrm{~K}$ (solid line in Figure 9). The $U_{e f f}$ value is very similar to those found in other monomeric Co(II) SMM [44]. This $U_{\text {eff }}$ value is lower than the predicted value from the $D$ value obtained in the fit of the DC magnetic properties and suggests that the quantum pathway operating at very low temperatures is not fully suppressed by the applied DC magnetic field of $800 \mathrm{G}$.

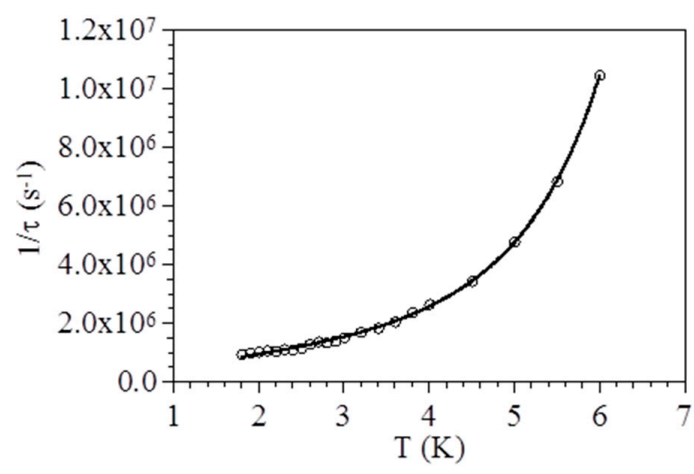

Figure 9. Inverse relaxation time $(1 / \tau)$ of compound 1 in the temperature range $2-6 \mathrm{~K}$. Solid line is the fit to Equation (5). 


\section{Materials and Methods}

\subsection{Syntheses}

All solvents were of reagent grade and used without further purification. Cobalt perchlorate, acetic hydrazide and salicylaldehyde were purchased from Sigma Aldrich, Saint Quentin Fallavier Cedex, France and used as received.

\subsubsection{Synthesis of the Hydrazone Ligand [HL]}

The ligand HL [(E)-N'-(2-hydroxybenzylidene)acetohydrazide] was prepared by the condensation of acetic hydrazide $(0.74 \mathrm{~g}, 10 \mathrm{mmol})$ with salicylaldehyde $(1.221 \mathrm{~g}, 10 \mathrm{mmol})$ in methanol medium $(100 \mathrm{~mL})$. On refluxing the methanolic solution at $65^{\circ} \mathrm{C}$ for $5 \mathrm{~h}$ a colourless solution was obtained. The solvent was removed under reduced pressure and the white residue was purified by recrystallization to obtain colourless shiny crystals. Yield $0.155 \mathrm{~g}$ (87\%). Anal. Calcd. (\%) for $\mathrm{C}_{9} \mathrm{H}_{10} \mathrm{~N}_{2} \mathrm{O}_{2}(\mathrm{M}=178.1 \mathrm{~g} / \mathrm{mol}): \mathrm{C}, 60.66 ; \mathrm{H}, 5.66 ; \mathrm{N}, 15.72$. Found: $\mathrm{C}, 60.58 ; \mathrm{H}, 5.78 ; \mathrm{N}, 15.69$. FT-IR bands $\left(\mathrm{cm}^{-1}\right): v_{(\mathrm{C}=\mathrm{N})} 1601, v_{(\mathrm{C}=\mathrm{O})} 1669$.

\subsubsection{Synthesis of $\left[\mathrm{Co}(\mathrm{HL})_{2}\right]\left(\mathrm{ClO}_{4}\right)_{2} \cdot 2 \mathrm{H}_{2} \mathrm{O}(\mathbf{1})$}

$\mathrm{Co}\left(\mathrm{ClO}_{4}\right)_{2} \cdot 6 \mathrm{H}_{2} \mathrm{O}(0.55 \mathrm{~g}, 1.5 \mathrm{mmol})$ was dissolved in $10 \mathrm{~mL}$ of a $1: 1$ methanol-acetonitrile mixture and $0.25 \mathrm{mmol}(0.045 \mathrm{~g})$ of the ligand HL were added. The mixture was stirred for $1 / 2 \mathrm{~h}$ at $60{ }^{\circ} \mathrm{C}$. The resulting orange solution was kept at room temperature for slow evaporation. Orange octahedral single crystals suitable for $\mathrm{X}$-ray diffraction were obtained within a week. Yield $0.05 \mathrm{~g}$ (64\%). Anal. Calcd. (\%) for $\mathrm{C}_{12} \mathrm{H}_{16} \mathrm{Cl}_{2} \mathrm{CoN}_{4} \mathrm{O}_{13}(\mathrm{M}=650.24 \mathrm{~g} / \mathrm{mol})$ : $\mathrm{C}, 22.16 ; \mathrm{H}, 2.48 ; \mathrm{N}, 8.62$. Found: $\mathrm{C}, 21.98 ; \mathrm{H}$, 2.78; N, 8.29. Main FT-IR bands. $v_{\mathrm{C}=\mathrm{N}} 1548, v_{\mathrm{C}=\mathrm{O}} 1602, v_{\mathrm{N}-\mathrm{H}} 2843, v_{\mathrm{Co}-\mathrm{N}} 452 \mathrm{~cm}^{-1}$.

\subsection{Physical Measurements}

C, $\mathrm{H}$ and $\mathrm{N}$ microanalyses were carried out with a Perkin-Elmer 2400 II elemental analyzer. FT-IR spectra were recorded on a Thermal Scientific Nicolet ${ }^{\mathrm{TM}} 6700$ ATR (attenuated total reflection) spectrometer equipped with a Smart iTR diamond window. The magnetic susceptibility measurements were carried out in the temperature range 1.85-300 $\mathrm{K}$ with an applied magnetic field of $0.1 \mathrm{~T}$ on a polycrystalline sample of $\mathbf{1}$ (with a mass of $9.8 \mathrm{mg}$ ) sealed in a polypropylene bag with mineral oil to avoid the field orientation of the sample with a Quantum Design VSM susceptometer. The isothermal magnetization was performed on the same sample at 1.9,3,5 and $8 \mathrm{~K}$ with magnetic fields up to 9 T. AC susceptibility measurements were performed in a PPMS-9 Quantum Design susceptometer with an oscillating field of 1 to 6 Oe with a frequency from 1 to $10,000 \mathrm{~Hz}$. Prior to the experiments, the field dependent magnetization was measured at $100 \mathrm{~K}$ in order to detect the presence of any bulk ferromagnetic impurities. The samples appeared to be free of any significant ferromagnetic impurities. The data were corrected for the sample holder and the intrinsic diamagnetic contributions.

\subsection{X-ray Crystallography}

Intensity data were collected using $\mathrm{MoK} \alpha$ radiation with a Bruker ApexII CCD diffractometer at $120 \mathrm{~K}$ for 1 . Data collection and data reduction were performed with SHELX [45] programs. The structures were solved by direct method using the program SIR92 [46] and refined with the program CRYSTALS [47]. Empirical absorption corrections were carried out by multi scan technique [48]. All non-hydrogen atoms were refined anisotropically by full-matrix least-squares based on $F$. All other $\mathrm{H}$ atoms were generated geometrically and were included in the refinement by the riding model approximation. Selected crystallographic data, experimental conditions and relevant features of the structural refinements are listed in Table 4. 
Table 4. Crystal Data of compound 1.

\begin{tabular}{|c|c|}
\hline & 1 \\
\hline Formula & $\mathrm{C}_{12} \mathrm{H}_{16} \mathrm{Cl}_{2} \mathrm{CoN}_{4} \mathrm{O}_{13}$ \\
\hline Mol. Wt. $\left(\mathrm{g} \mathrm{mol}^{-1}\right)$ & 650.24 \\
\hline$T(\mathrm{~K})$ & 120 \\
\hline$\lambda \AA$ & 0.71073 \\
\hline Crystal system & Triclinic \\
\hline Space gr. & P-1 \\
\hline$a(\AA)$ & 10.1953(13) \\
\hline$b(\AA)$ & $10.5394(14)$ \\
\hline$c(\AA)$ & 13.6540(18) \\
\hline$\alpha\left({ }^{\circ}\right)$ & $78.889(6)$ \\
\hline$\beta\left(^{\circ}\right)$ & $69.501(6)$ \\
\hline$\gamma\left({ }^{\circ}\right)$ & $69.266(6)$ \\
\hline$V \AA^{3}$ & $1281.3(3)$ \\
\hline Z & 2 \\
\hline$D$ g.cm ${ }^{-3}$ & 1.685 \\
\hline$\mu \mathrm{mm}^{-1}$ & 0.956 \\
\hline$F(000)$ & 666 \\
\hline Crystal size $\mathrm{mm}^{3}$ & $0.08 \times 0.10 \times 0.17$ \\
\hline$\theta$ range $^{\circ}$ & 2 to 28 \\
\hline Reflections collected & 47,212 \\
\hline Ind. reflections & 6201 \\
\hline$R($ int $)$ & 0.037 \\
\hline Reflections used & 4781 \\
\hline Parameters refined & 391 \\
\hline$S$ & 1.07 \\
\hline Final $R$ indices & $R=0.0451$ \\
\hline$[I>3 \sigma(I)]$ & $w R=0.0524$ \\
\hline$\Delta \rho_{\max }$ and $\Delta \rho_{\min } \mathrm{e} \cdot \AA^{-3}$ & 0.7 and -1.14 \\
\hline
\end{tabular}

\section{Conclusions}

A new octahedral mononuclear Co(II) complex has been synthesized with a ONO donor hydrazone Schiff base ligands featuring a meridional geometry. The magnetic susceptibility and isothermal magnetization at different temperatures allows the determination of a large negative ZFS parameter $(D)$ implying the presence of an easy axis of the anisotropy. Additionally, the mononuclear complex exhibits field induced frequency dependent slow magnetization that can be fit with the Debye model with an $\alpha$ parameter close to zero in the studied temperature range, indicating a narrow distribution of the relaxation times and a single relaxation process. The relaxation times can be fit to the simultaneous presence of Orbach, Raman and single phonon direct processes.

Funding: This research was funded by Initiative d'excellence de l'Université de Bordeaux post-doctoral program, the Spanish MINECO (project CTQ2017-87201-P AEI/FEDER, EU) and the Generalitat Valenciana (project Prometeo II/2014/076).

Author Contributions: Data adquisition: D.S. and M.R.; Formal analysis: C.J.G.-G.; Project administration: D.S.; Writing-review \& editing: P.G.

Acknowledgments: D.S. is thankful to Rodolphe Clérac and the CRPP administrative team for facilitating the research.

Conflicts of Interest: The authors declare no conflict of interest. The funders had no role in the design of the study; in the collection, analyses, or interpretation of data; in the writing of the manuscript, and in the decision to publish the results.

Notes: Crystallographic data for the structure reported in this paper have been deposited with the Cambridge Crystallographic Data Center as supplementary publication no. CCDC-1870221. Copies of the data can be obtained free of charge on application to CCDC, 12, Union Road, Cambridge, CB2 1EZ, UK (fax: +44-1223-336033); e-mail: deposit@ccdc.cam.ac.uk. 


\section{References}

1. Vincent, R.; Klyatskaya, S.; Ruben, M.; Wernsdorfer, W.; Balestro, F. Electronic read-out of a single nuclear spin using a molecular spin transistor. Nature 2012, 488, 357-360. [CrossRef] [PubMed]

2. Aromí, G.; Aguilà, D.; Gamez, P.; Luis, F.; Roubeau, O. Design of magnetic coordination complexes for quantum computing. Chem. Soc. Rev. 2012, 41, 537-546. [CrossRef]

3. Timco, G.A.; Faust, T.B.; Tuna, F.; Winpenny, R.E.P. Linking heterometallic rings for quantum information processing and amusement. Chem. Soc. Rev. 2011, 40, 3067-3075. [CrossRef] [PubMed]

4. Ishikawa, N.; Sugita, M.; Ishikawa, T.; Koshihara, S.Y.; Kaizu, Y. Lanthanide Double-Decker Complexes Functioning as Magnets at the Single-Molecular Level. J. Am. Chem. Soc. 2003, 125, 8694-8695. [CrossRef] [PubMed]

5. Ishikawa, N.; Sugita, M.; Ishikawa, T.; Koshihara, S.; Kaizu, Y. Mononuclear Lanthanide Complexes with a Long Magnetization Relaxation Time at High Temperatures: A New Category of Magnets at the Single-Molecular Level. J. Phys. Chem. B 2004, 108, 11265-11271. [CrossRef]

6. AlDamen, M.A.; Clemente-Juan, J.M.; Coronado, E.; Marti-Gastaldo, C.; Gaita-Arino, A. Mononuclear lanthanide single-molecule magnets based on polyoxometalates. J. Am. Chem. Soc. 2008, 130, 8874-8875. [CrossRef] [PubMed]

7. AlDamen, M.A.; Cardona-Serra, S.; Clemente-Juan, J.M.; Coronado, E.; Alejandro, G.-A.; Carlos, M.-G.; Fernando, L.; Oscar, M. Mononuclear Lanthanide Single Molecule Magnets Based on the Polyoxometalates $\left[\mathrm{Ln}\left(\mathrm{W}_{5} \mathrm{O}_{18}\right)_{2}\right]^{9-}$ and $\left[\operatorname{Ln}\left(\beta_{2}-\mathrm{SiW}_{11} \mathrm{O}_{39}\right)_{2}\right]^{13-}\left(\mathrm{Ln}^{\mathrm{III}}=\mathrm{Tb}, \mathrm{Dy}, \mathrm{Ho}, \mathrm{Er}, \mathrm{Tm}\right.$, and $\left.\mathrm{Yb}\right)$. Inorg. Chem. 2009, 48, 3467-3479. [CrossRef]

8. Baldoví, J.J.; Cardona-Serra, S.; Clemente-Juan, J.M.; Coronado, E.; Gaita-Arin, A.; Palii, A. Rational Design of Single-Ion Magnets and Spin Qubits Based on Mononuclear Lanthanoid Complexes. Inorg. Chem. 2012, 51, 12565-12574. [CrossRef]

9. Rinehart, J.D.; Long, J.R. Slow magnetic relaxation in a trigonal prismatic uranium(III) complex. J. Am. Chem. Soc. 2009, 131, 12558-12559. [CrossRef]

10. Rinehart, J.D.; Meihaus, K.R.; Long, J.R. Observation of a Secondary Slow Relaxation Process for the

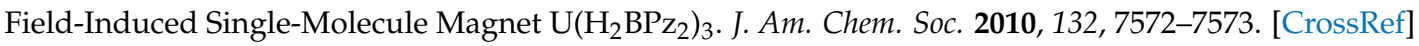

11. Magnani, N.; Apostolidis, C.; Morgenstern, A.; Colineau, E.; Griveau, J.C.; Bolvin, H.; Walter, O.; Caciuffo, R. Magnetic memory effect in a transuranic mononuclear complex. Angew. Chem. Int. Ed. 2011, 50, 1696-1698. [CrossRef] [PubMed]

12. Antunes, M.A.; Pereira, L.C.J.; Santos, I.C.; Mazzanti, M.; Marçalo, J.; Almeida, M. [U(Tp $\left.{ }^{\mathrm{Me} 2}\right)_{2}(\text { bipy) }]^{+}$: A Cationic Uranium(III) Complex with Single-Molecule-Magnet Behavior. Inorg. Chem. 2011, 50, 9915-9917. [CrossRef] [PubMed]

13. Goodwin, C.A.P.; Ortu, F.; Reta, D.; Chilton, N.F.; Mills, D.P. Molecular magnetic hysteresis at 60 kelvin in dysprosocenium. Nature 2017, 548, 439-442. [CrossRef] [PubMed]

14. Guo, F.-S.; Day, B.M.; Chen, Y.-C.; Tong, M.-L.; Mansikkamäki, A.; Layfield, R.A. A Dysprosium Metallocene Single-Molecule Magnet Functioning at the Axial Limit. Angew. Chem. Int. Ed. 2017, 56, 11445-11449. [CrossRef] [PubMed]

15. Guo, F.-S.; Day, B.M.; Chen, Y.-C.; Tong, M.-L.; Mansikkamäki, A.; Layfield, R.A. Magnetic hysteresis up to 80 kelvin in a dysprosium metallocene single-molecule magnet. Science 2018. [CrossRef] [PubMed]

16. Gómez-Coca, S.; Cremades, E.; Aliaga-Alcalde, N.; Ruiz, E. Mononuclear Single-Molecule Magnets: Tailoring the Magnetic Anisotropy of First-Row Transition-Metal Complexes. J. Am. Chem. Soc. 2013, 135, 7010-7018. [CrossRef] [PubMed]

17. Freedman, D.E.; Harman, W.H.; Harris, T.D.; Long, G.J.; Chang, C.J.; Long, J.R. Slow Magnetic Relaxation in a High-Spin Iron(II) Complex. J. Am. Chem. Soc. 2010, 132, 1224-1225. [CrossRef]

18. Harman, W.H.; Harris, T.D.; Freedman, D.E.; Fong, H.; Chang, A.; Rinehart, J.D.; Ozarowski, A.; Sougrati, M.T.; Grandjean, F.; Long, G.J.; et al. Slow magnetic relaxation in a family of trigonal pyramidal iron(II) pyrrolide complexes. J. Am. Chem. Soc. 2010, 132, 18115-18126. [CrossRef]

19. Rechkemmer, Y.; Breitgoff, F.D.; van der Meer, M.; Atanasov, M.; Hakl, M.; Orlita, M.; Neugebauer, P.; Neese, F.; Sarkar, B.; van Slageren, J. A four-coordinate cobalt(II) single-ion magnet with coercivity and a very high energy barrier. Nat. Commun. 2016, 7, 10467. [CrossRef] 
20. Ruamps, R.; Batchelor, L.J.; Guillot, R.; Zakhia, G.; Barra, A.-L.; Wernsdorfer, W.; Guihéry, N.; Mallah, T. Ising-type magnetic anisotropy and single molecule magnet behaviour in mononuclear trigonal bipyramidal Co(II) complexes. Chem. Sci. 2014, 5, 3418-3424. [CrossRef]

21. Poulten, R.C.; Page, M.J.; Algarra, A.G.; Le Roy, J.J.; López, I.; Carter, E.; Llobet, A.; Macgregor, S.A.; Mahon, M.F.; Murphy, D.M.; et al. Synthesis, Electronic Structure, and Magnetism of $\left[\mathrm{Ni}(6-\mathrm{Mes})_{2}\right]^{+}$: A Two-Coordinate Nickel(I) Complex Stabilized by Bulky NHeterocyclic Carbenes. J. Am. Chem. Soc. 2013, 135, 13640-13643. [CrossRef] [PubMed]

22. Jurca, T.; Farghal, A.; Lin, P.-H.; Korobkov, I.; Murugesu, M.; Richeson, D.S.J. Single-Molecule Magnet Behavior with a Single Metal Center Enhanced through Peripheral Ligand Modifications. Am. Chem. Soc. 2011, 133, 15814-15817. [CrossRef] [PubMed]

23. Zadrozny, J.M.; Long, J.R. Slow Magnetic Relaxation at Zero Field in the Tetrahedral Complex $\left[\mathrm{Co}(\mathrm{SPh})_{4}\right]^{2-}$. J. Am. Chem. Soc. 2011, 133, 20732-20734. [CrossRef] [PubMed]

24. Saber, M.R.; Dunbar, K.R. Ligands effects on the magnetic anisotropy of tetrahedral cobalt complexes. Chem. Commun. 2014, 50, 12266-12269. [CrossRef] [PubMed]

25. Smolko, L.; Černak, J.; Dušek, M.; Miklovič, J.; Titiš, J.; Boča, R. Three tetracoordinate Co(II) complexes [Co(biq) $\left.\mathrm{X}_{2}\right](\mathrm{X}=\mathrm{Cl}, \mathrm{Br}, \mathrm{I})$ with easy-plane magnetic anisotropy as field-induced single-molecule magnets. Dalton Trans. 2015, 44, 17565-17571. [CrossRef]

26. Vaidya, S.; Upadhyay, A.; Singh, S.K.; Gupta, T.; Tewary, S.; Langley, S.K.; Walsh, J.P.S.; Murray, K.S.; Rajaraman, G.; Shanmugam, M. A synthetic strategy for switching the single ion anisotropy in tetrahedral Co(II) complexes. Chem. Commun. 2015, 51, 3739-3742. [CrossRef]

27. Vaidya, S.; Singh, S.K.; Shukla, P.; Ansari, K.; Rajaraman, G.; Shanmugam, M. Role of Halide Ions on the Nature of Magnetic Anisotropy in Tetrahedral Co(II) Complexes. Chem. A Eur. J. 2017, 23, 9546-9559. [CrossRef]

28. Zadrozny, J.M.; Telser, J.; Long, J.R. Slow magnetic relaxation in the tetrahedral cobalt(II) complexes $\left[\mathrm{Co}(\mathrm{EPh})_{4}\right]_{2}(\mathrm{E}=\mathrm{O}, \mathrm{S}, \mathrm{Se})$. Polyhedron 2013, 64, 209-217. [CrossRef]

29. Vallejo, J.; Castro, I.; Ruiz-Garcia, R.; Cano, J.; Julve, M.; Lloret, F.; De Munno, G.; Wernsdorfer, W.; Pardo, E. Field-Induced Slow Magnetic Relaxation in a Six-Coordinate Mononuclear Cobalt(II) Complex with a Positive Anisotropy. J. Am. Chem. Soc. 2012, 134, 15704-15707. [CrossRef]

30. Colacio, E.; Ruiz, J.; Ruiz, E.; Cremades, E.; Krzystek, J.; Carretta, S.; Cano, J.; Guidi, T.; Wernsdorfer, W.; Brechin, E.K. Slow magnetic relaxation in a Co(II)-Y(III) single-ion magnet with positive axial zero-field splitting. Angew. Chem. Int. Ed. 2013, 52, 9130-9134. [CrossRef]

31. Herchel, R.; Vahovska, L.; Potočňak, I.; Travniček, Z. Slow Magnetic Relaxation in Octahedral Cobalt(II) Field-Induced Single-Ion Magnet with Positive Axial and Large Rhombic Anisotropy. Inorg. Chem. 2014, 53, 5896-5898. [CrossRef] [PubMed]

32. Diaz-Torres, R.; Menelaou, M.; Roubeau, O.; Sorrenti, A.; Brandariz-de-Pedro, G.; Sanudo, E.C.; Teat, S.J.; Fraxedas, J.; Ruiz, E.; Aliaga-Alcalde, N. Multiscale study of mononuclear $\mathrm{CO}^{\mathrm{II}}$ SMMs based on curcuminoid ligands. Chem. Sci. 2016, 7, 2793-2803. [CrossRef] [PubMed]

33. Palii, A.V.; Korchagin, D.V.; Yureva, E.A.; Akimov, A.V.; Misochko, E.Y.; Shilov, G.V.; Talantsev, A.D.; Morgunov, R.B.; Aldoshin, S.M.; Tsukerblat, B.S. Single-Ion Magnet $\mathrm{Et}_{4} \mathrm{~N}\left[\mathrm{Co}{ }^{\mathrm{II}}(\mathrm{hfac})_{3}\right]$ with Nonuniaxial Anisotropy: Synthesis, Experimental Characterization, and Theoretical Modeling. Inorg. Chem. 2016, 55, 9696-9706. [CrossRef] [PubMed]

34. Valigura, D.; Rajnak, C.; Moncol, J.; Titiš, J.; Boča, R. A mononuclear Co(II) complex formed from pyridinedimethanol with manifold slow relaxation channels. Dalton Trans. 2017, 46, 10950-10956. [CrossRef]

35. Varga, F.; Rajnak, C.; Titis, J.; Moncol, J.; Boca, R. Slow magnetic relaxation in a Co(II) octahedraltetrahedral system formed of a $\left[\mathrm{CoL}_{3}\right]^{2+}$ core with $\mathrm{L}=$ bis(diphenylphosphanoxido) methane and tetrahedral $\left[\mathrm{CoBr}_{4}\right]^{2-}$ counter anions. Dalton Trans. 2017, 46, 4148-4151. [CrossRef] [PubMed]

36. Gómez-Coca, S.; Urtizberea, A.; Cremades, E.; Alonso, P.J.; Camon, A.; Ruiz, E.; Luis, F. Origin of slow magnetic relaxation in Kramers ions with non-uniaxial anisotropy. Nat. Commun. 2014, 5, 4300. [CrossRef]

37. Sertphon, D.; Murray, K.S.; Phonsri, W.; Jover, J.; Ruiz, E.; Telfer, S.G.; Alkaş, A.; Harding, P.; Harding, D.J. Slow Relaxation of Magnetization in a Bis-mer-Tridentate Octahedral Co(II) Complex. Dalton Trans. 2018, 47, 859-867. [CrossRef]

38. Zhu, Y.-Y.; Cui, C.; Zhang, Y.-Q.; Jia, J.-H.; Guo, X.; Gao, C.; Qian, K.; Jiang, S.-D.; Wang, B.-W.; Wang, Z.-M.; et al. Zero-field slow magnetic relaxation from single $\mathrm{Co}(\mathrm{II})$ ion: A transition metal single-molecule magnet with high anisotropy barrier. Chem. Sci. 2013, 4, 1802-1806. [CrossRef] 
39. Peng, Y.; Mereacre, V.; Anson, C.E.; Zhang, Y.; Bodenstein, T.; Fink, K.; Powell, A.K. Field-Induced Co(II) Single-Ion Magnets with mer-Directing Ligands but Ambiguous Coordination Geometry. Inorg. Chem. 2017, 56, 6056-6066. [CrossRef]

40. Mabbs, F.E.; Machin, D.J. Magnetism and Transition Metal Complexes; Dover Publications: New York, NY, USA, 2008.

41. Chilton, N.F.; Anderson, R.P.; Turner, L.D.; Soncini, A.; Murray, K.S. PHI: Apowerful new program for the analysis of anisotropic monomeric and exchange-coupled polynuclear $\mathrm{d}$ - and $\mathrm{f}$ block complexes. J. Comput. Chem. 2013, 34, 1164-1175. [CrossRef]

42. Aubin, S.M.J.; Sun, Z.; Pardi, L.; Krzystek, J.; Folting, K.; Brunel, L.; Rheingold, A.L.; Christou, G.; Hendrickson, D.N. Reduced Anionic $\mathrm{Mn}_{12}$ Molecules with Half-Integer Ground States as Single-Molecule Magnets. Inorg. Chem. 1999, 38, 5329. [CrossRef]

43. Hagiwara, M.; Nagata, K. Magnetic behaviors of complex nature found in an oxide glass system containing deposited magnetite clusters at the superparamagnetic state. J. Magn. Magn. Mater. 1998, 177-181, 91-92. [CrossRef]

44. Chandrasekhar, V.; Dey, A.; Mota, A.J.; Colacio, E. Slow Magnetic Relaxation in Co(III)-Co(II) Mixed-Valence Dinuclear Complexes with a $\mathrm{Co}^{\mathrm{II}} \mathrm{O}_{5} \mathrm{X}\left(\mathrm{X}=\mathrm{Cl}, \mathrm{Br}, \mathrm{NO}_{3}\right)$ Distorted-Octahedral Coordination Sphere. Inorg. Chem. 2013, 52, 4554-4561. [CrossRef] [PubMed]

45. Sheldrick, G.M. A short history of SHELX. Acta Crystallogr. A 2008, 64, 112-122. [CrossRef] [PubMed]

46. Altomare, A.; Burla, M.C.; Camalli, M.; Cascarano, G.L.; Giacovazzo, C.; Guagliardi, A.; Moliterni, A.G.G.; Polidori, G.; Spagna, R.J. SIR97: A new tool for crystal structure determination and refinement. Appl. Cryst. 1999, 32, 115-119. [CrossRef]

47. Betteridge, P.W.; Carruthers, J.R.; Cooper, R.I.; Prout, K.; Watkin, D.J. CRYSTALS version 12: software for guided crystal structure analysis. J. Appl. Cryst. 2003, 36, 1487. [CrossRef]

48. Meulenaer, J.D.; Tompa, H. The absorption correction in crystal structure analysis. Acta Crystallogr. 1965, 19, 1014-1018. [CrossRef] 